\title{
Predictors of Incomplete Occlusion following Pipeline Embolization of Intracranial Aneurysms: Is It Less Effective in Older Patients?
}

\author{
(D) N. Adeeb, (D).M. Moore, (DM. Wirtz, DC.J. Griessenauer, DP.M. Foreman, DH. Shallwani, DR. Gupta, (D)A.A. Dmytriw, \\ (D) R. Motiei-Langroudi, (D)A. Alturki, (D) M.R. Harrigan, (D)A.H. Siddiqui, (DE.I. Levy, (D)A.J. Thomas, and (D).S. Ogilvy
}

\begin{abstract}
BACKGROUND AND PURPOSE: Flow diversion with the Pipeline Embolization Device (PED) for the treatment of intracranial aneurysms is associated with a high rate of aneurysm occlusion. However, clinical and radiographic predictors of incomplete aneurysm occlusion are poorly defined. In this study, predictors of incomplete occlusion at last angiographic follow-up after PED treatment were assessed.
\end{abstract}

MATERIALS AND METHODS: A retrospective analysis of consecutive aneurysms treated with the PED between 2009 and 2016 , at 3 academic institutions in the United States, was performed. Cases with angiographic follow-up were selected to evaluate factors predictive of incomplete aneurysm occlusion at last follow-up.

RESULTS: We identified 465 aneurysms treated with the PED; 380 (81.7\%) aneurysms (329 procedures; median age, 58 years; female/male ratio, 4.8:1) had angiographic follow-up, and were included. Complete occlusion (100\%) was achieved in $78.2 \%$ of aneurysms. Near-complete (90\%-99\%) and partial (<90\%) occlusion were collectively achieved in $21.8 \%$ of aneurysms and defined as incomplete occlusion. Of aneurysms followed for at least 12 months (211 of 380), complete occlusion was achieved in $83.9 \%$. Older age (older than 70 years), nonsmoking status, aneurysm location within the posterior communicating artery or posterior circulation, greater aneurysm maximal diameter ( $\geq 21 \mathrm{~mm}$ ), and shorter follow-up time ( $<12$ months) were significantly associated with incomplete aneurysm occlusion at last angiographic follow-up on univariable analysis. However, on multivariable logistic regression, only age, smoking status, and duration of follow-up were independently associated with occlusion status.

CONCLUSIONS: Complete occlusion following PED treatment of intracranial aneurysms can be influenced by several factors related to the patient, aneurysm, and treatment. Of these factors, older age (older than 70 years) and nonsmoking status were independent predictors of incomplete occlusion. While the physiologic explanation for these findings remains unknown, identification of factors predictive of incomplete aneurysm occlusion following PED placement can assist in patient selection and counseling and might provide insight into the biologic factors affecting endothelialization.

ABBREVIATION: PED = Pipeline Embolization Device

$\mathbf{T}$ he flow-diverting Pipeline Embolization Device (PED; Covidien, Irvine, California) has become a mainstay for the treatment of intracranial aneurysms. ${ }^{1}$ The device was approved by the US Food and Drug Administration in 2011 for the treatment of

Received February 3, 2017; accepted after revision July 8

From the Neurosurgical Service (N.A., J.M.M., M.W., C.J.G., R.G., A.A.D., R.M.-L., A.A., A.J.T., C.S.O.), Beth Israel Deaconess Medical Center, Harvard Medical School, Boston, Massachusetts; Department of Neurosurgery (P.M.F., M.R.H.), University of Alabama at Birmingham, Birmingham, Alabama; Department of Neurosurgery (H.S. A.H.S., E.I.L.), State University of New York at Buffalo, Buffalo, New York; and Department of Neurosurgery (N.A.), Louisiana State University, Shreveport, Louisiana. Nimer Adeeb and Justin M. Moore contributed equally to this work.

Please address correspondence to Christopher S. Ogilvy, MD, Neurosurgical Service, Beth Israel Deaconess Medical Center, Harvard Medical School, 110 Francis St, Suite 3B, Boston, MA 02215-5501; e-mail: cogilvy@bidmc.harvard.edu

三 Indicates article with supplemental on-line table.

http://dx.doi.org/10.3174/ajnr.A5375 large or giant, wide-neck brain aneurysms along the internal carotid artery in adults. ${ }^{2}$ Numerous studies have since demonstrated the safety and efficacy of the PED in treating aneurysms with varying morphologies in different anatomic locations. ${ }^{3-8}$ As the clinical indications for PED placement expand, predictors of radiographic outcomes have become a topic of ongoing investigation. Although 1 study found that fusiform aneurysm morphology and shorter follow-up length were independent predictors of incomplete occlusion, this study was limited by a small sample size and a mean follow-up of 6.1 months. ${ }^{9}$ The expanding use of PEDs for treating intracranial aneurysms necessitates an evaluation of predictors of incomplete occlusion.

\section{MATERIALS AND METHODS}

A retrospective analysis of consecutive aneurysms treated with PED placement between 2009 and 2016 at 3 academic institutions 
(Beth Israel Deaconess Medical Center; Department of Neurosurgery, University of Alabama at Birmingham; and State University of New York at Buffalo) in United States was performed. Inclusion criteria consisted of all adult patients with intracranial aneurysms treated with the PED who had undergone angiographic follow-up. Both ruptured and unruptured aneurysms were included; all aneurysm morphologies (ie, saccular, blister, fusiform, dissecting) and intracranial locations were included. Institutional review board approval was obtained at all 3 centers before the commencement of the study. We collected the following information: patient demographics, aneurysm and PED characteristics, procedural complications, and angiographic and functional outcomes.

\section{Procedural Details}

Patients received aspirin, $325 \mathrm{mg}$, and clopidogrel, $75 \mathrm{mg}$ daily, for 3-14 days before the intervention. Platelet function testing was routinely performed with a whole-blood Lumi-Aggregometer (Chrono-Log, Havertown, Pennsylvania), light transmission aggregometry, or the VerifyNow P2Y12 assay (Accumetrics, San Diego, California). Clopidogrel nonresponders were identified on the basis of established cutoff values at the individual institutions, and manufacturers' recommendations were used for guidance. If a patient was identified as a clopidogrel responder, the clopidogrel was continued. If a patient was identified as a clopidogrel nonresponder, the choice to continue the same dose of clopidogrel, administer a 1-time 600-mg clopidogrel boost within the 24 hours before the procedure, or switch to ticagrelor was at the discretion of the interventionalist performing the procedure. Patients undergoing treatment of a ruptured aneurysm received a loading dose of aspirin, $650 \mathrm{mg}$, and clopidogrel, $600 \mathrm{mg}$, before the intervention.

Patients underwent local anesthesia with sedation or general anesthesia at the discretion of the individual institutions, and all patients were anticoagulated with heparin throughout the procedure. The type of guide catheter and microcatheter used for PED deployment was at the discretion of the individual institutions. The deployment and apposition of the PED to the ICA wall was documented by fluoroscopy. Dual-antiplatelet therapy was continued for at least 3 months after the procedure, and aspirin was continued indefinitely thereafter.

\section{Angiographic Outcome}

Angiographic outcome was assessed with digital subtracted angiography or MR angiography ${ }^{10,11}$ on the basis of the follow-up protocols at the discretion of each individual institution. In 1 institution, patients were imaged and reviewed at 6 months postprocedure with DSA, then at 2 and 5 years with DSA or MRA. In the second institution, patients were reviewed at 6 and 12 months postprocedure with MRA, then annually until 5 years with MRA. In the third institution, patients were followed at 3 and 6 months postprocedure with MRA, at 12 months with DSA, and then annually until 5 years with MRA. Aneurysm occlusion on follow-up DSA was assessed by the treating interventionalist. Follow-up MRAs were assessed by a radiologist blinded to the clinical history and an interventionalist. Occlusion was categorized as complete occlusion (100\%), near-complete occlusion (90\%$100 \%)$, and partial occlusion $(<90 \%)$. Both near-complete and partial occlusion were collectively defined as incomplete occlusion.

\section{Outcome}

Functional outcome was assessed with the modified Rankin Scale at last follow-up by the interventionalist at each institution.

\section{Statistical Analysis}

Statistical analysis was performed with SPSS 21.0 (IBM, Armonk, New York). In univariable analysis, variables were compared among groups with the nonparametric test for continuous variables and the $\chi^{2}$ test for categoric variables, to identify predictors of incomplete occlusion. Statistical significance was defined as $P<.05$. Multivariable logistic regression was performed on candidate predictor variables to identify variables independently associated with incomplete occlusion at last angiographic follow-up after controlling for potential confounders.

\section{RESULTS}

\section{Baseline and Aneurysm Characteristics}

A total of 465 aneurysms treated with PED placement at the 3 institutions were identified. Of these, 380 (81.7\%) aneurysms treated by 329 PED procedures (median age, 58 years; female/ male ratio, 4.8:1) had angiographic follow-up and were included in this study. Current smoking and multiple aneurysms were present in $25.8 \%$ and $45 \%$ of procedures, respectively. The pretreatment mRS was $0-2$ in $95.4 \%$ of procedures and 3-5 in $4.6 \%$. Treatment in the setting of immediate aneurysmal subarachnoid hemorrhage occurred in 3\% of procedures. Aneurysms were mostly located along the ICA $(83.2 \%)$, followed by the posterior circulation (13.4\%). Most aneurysms were saccular (67.6\%) or fusiform (26.9\%). The median maximal diameter and neck size were 7.7 and $4 \mathrm{~mm}$, respectively. A daughter sac was present in $24.7 \%$ of aneurysms (Table 1 ).

\section{Treatment Outcome}

A single PED was used in the treatment of $77.5 \%$ of procedures, while $\geq 2$ PEDs were placed in $22.5 \%$. The median length of angiographic follow-up was 13.5 months (mean, 19.2 months). At last follow-up, complete occlusion $(100 \%)$ was achieved in $78.2 \%$ of aneurysms, while near-complete occlusion (90\%-99\%) was achieved in $7.6 \%$, and partial occlusion $(<90 \%)$, in $14.2 \%$. Of aneurysms followed for at least 12 months (211 of 380), complete occlusion was achieved in $83.9 \%$. Retreatment was performed in $6.3 \%$ of aneurysms and was exclusively endovascular. At last follow-up, the mRS scores improved in $33.4 \%$ and worsened in $8.8 \%$; this percentage included patients presenting with aneurysmal SAH. Symptomatic thromboembolic complications were encountered in $5.2 \%$ of procedures, and symptomatic hemorrhagic complications, in $1.8 \%$. The mortality rate was $1.2 \%$ ( 4 cases); this was due to either ischemic stroke ( 2 cases), early postprocedure hemorrhage ( 1 case), or pretreatment aneurysmal SAH (1 case) (Table 2).

\section{Predictors of Incomplete Occlusion}

On univariable analysis, older age (older than 70 years, $P=.002$ ), nonsmoking status $(P=.005)$, aneurysm location within the posterior communicating artery or posterior circulation $(P=.01)$, 
Table 1: Baseline characteristics

\begin{tabular}{|c|c|}
\hline Parameter & No. \\
\hline No. of procedures & 329 \\
\hline No. of aneurysms & 380 \\
\hline \multicolumn{2}{|l|}{ Sex } \\
\hline Female & $272(82.7 \%)$ \\
\hline Male & $57(17.3 \%)$ \\
\hline Median age (range) (yr) & $58(18-82)$ \\
\hline Smoking & $85(25.8 \%)$ \\
\hline Multiple aneurysms & $148(45 \%)$ \\
\hline \multicolumn{2}{|l|}{ Pretreatment mRS } \\
\hline $0-2$ & $314(95.4 \%)$ \\
\hline $3-5$ & $15(4.6 \%)$ \\
\hline \multicolumn{2}{|l|}{ Aneurysm location } \\
\hline \multicolumn{2}{|l|}{ ICA } \\
\hline Petrous & $7(1.8 \%)$ \\
\hline Cavernous & $63(16.6 \%)$ \\
\hline Paraophthalmic & $212(55.8 \%)$ \\
\hline PcomA & $34(9 \%)$ \\
\hline ACA/AcomA & $5(1.3 \%)$ \\
\hline MCA & $8(2.1 \%)$ \\
\hline Posterior circulation & $51(13.4 \%)$ \\
\hline \multicolumn{2}{|l|}{ Aneurysm shape } \\
\hline Saccular & $257(67.6 \%)$ \\
\hline Blister & $11(2.9 \%)$ \\
\hline Fusiform & $102(26.9 \%)$ \\
\hline Dissecting & $10(2.6 \%)$ \\
\hline \multicolumn{2}{|l|}{ Aneurysm measurements (median) (range) (mm) } \\
\hline Maximal diameter ${ }^{a}$ & $7.7(1-44.5)$ \\
\hline Neck size (for saccular aneurysms) ${ }^{b}$ & $4(1-15.6)$ \\
\hline Dome-to-neck ratio (for saccular aneurysms) ${ }^{b}$ & $1.3(0.4-3.5)$ \\
\hline Daughter sac & $94(24.7 \%)$ \\
\hline \multicolumn{2}{|l|}{ Subarachnoid hemorrhage } \\
\hline Acute ( $<2 w k)$ & $10(3 \%)$ \\
\hline Remote (>2 wk) & $32(9.7 \%)$ \\
\hline \multicolumn{2}{|l|}{ Prior treatment } \\
\hline Endovascular & $33(8.7 \%)$ \\
\hline Operation & $6(1.6 \%)$ \\
\hline Both & $4(1.1 \%)$ \\
\hline
\end{tabular}

Note:-ACA indicates anterior cerebral artery; PcomA, posterior communicating artery; AcomA, anterior communicating artery.

${ }^{a}$ Data are missing for 11 aneurysms.

${ }^{b}$ Data are missing for 41 aneurysms.

larger aneurysm maximal diameter $(\geq 21 \mathrm{~mm}, P=.03)$, and shorter follow-up time ( $<12$ months, $P=.001$ ) were associated with significantly higher rates of incomplete occlusion at last follow-up (On-line Table).

Significant predictors of incomplete occlusion at last follow-up in univariable analysis were further analyzed in multivariable logistic regression. Older age (older than 70 years; OR, 2; 95\% CI, 1.1-3.8; $P=.03$; Figure), nonsmoking status (OR, 2; 95\% CI, $1.1-3.9, P=.03$ ), and shorter follow-up time ( $<12$ months; OR, 2 ; 95\% CI, 1.2-3.5; $P=.007$ ) were independently associated with a higher rate of incomplete occlusion at last follow-up (Table 3 ).

\section{DISCUSSION}

In this study, we report a multicenter experience with PED placement for the treatment of intracranial aneurysms, with a focus on identifying predictors of incomplete occlusion at last angiographic follow-up. Complete occlusion was achieved in $79.7 \%$ of cases. Although several patient- and aneurysm-related factors were significantly associated with a higher rate of incomplete aneurysm occlusion on univariable analysis, only age, smoking sta-

Table 2: Outcome measures

\begin{tabular}{|c|c|}
\hline Parameter & No. \\
\hline \multicolumn{2}{|l|}{ No. of Pipelines } \\
\hline 1 & $255(77.5 \%)$ \\
\hline 2 & $52(15.8 \%)$ \\
\hline$\geq 3$ & $22(6.7 \%)$ \\
\hline \multicolumn{2}{|l|}{ Platelet function test } \\
\hline Yes & $316(96 \%)$ \\
\hline No & $13(4 \%)$ \\
\hline \multicolumn{2}{|l|}{ Clopidogrel responder } \\
\hline Yes & $228(72.2 \%)$ \\
\hline No & $88(27.8 \%)$ \\
\hline \multicolumn{2}{|l|}{ Nonresponders' treatment } \\
\hline Switch to ticagrelor & $27(30.7 \%)$ \\
\hline Clopidogrel boost & $39(44.3 \%)$ \\
\hline Same dose of clopidogrel & $22(25 \%)$ \\
\hline $\begin{array}{l}\text { Last angiographic follow-up (median) } \\
\text { (range) (mo) }\end{array}$ & $13.5(1-83)$ \\
\hline \multicolumn{2}{|l|}{ Follow-up occlusion rate } \\
\hline Complete (100\%) & $297(78.2 \%)$ \\
\hline Near-complete (90\%-99\%) & $29(7.6 \%)$ \\
\hline Partial (<90\%) & $54(14.2 \%)$ \\
\hline \multicolumn{2}{|l|}{ Retreatment } \\
\hline Endovascular & $24(6.3 \%)$ \\
\hline \multicolumn{2}{|l|}{ Posttreatment mRS } \\
\hline $0-2$ & $314(95.6 \%)$ \\
\hline $3-5$ & $11(3.3 \%)$ \\
\hline 6 (Death) & $4(1.2 \%)$ \\
\hline \multicolumn{2}{|l|}{ Follow-up mRS } \\
\hline Improved & $110(33.4 \%)$ \\
\hline No change & $190(57.8 \%)$ \\
\hline Worsened & $29(8.8 \%)$ \\
\hline \multicolumn{2}{|l|}{ Neurologic complications } \\
\hline Thromboembolic & $31(9.4 \%)$ \\
\hline Symptomatic & $17(5.2 \%)$ \\
\hline Hemorrhagic & $11(3.3 \%)$ \\
\hline Symptomatic & $6(1.8 \%)$ \\
\hline
\end{tabular}

tus, and length of follow-up were independently associated with occlusion status.

\section{Predictors of Aneurysm Occlusion}

Predictors of complete occlusion and recanalization following endovascular treatment of intracranial aneurysms have been recently studied. ${ }^{12-14}$ Ruptured aneurysms, smaller maximal diameter, smaller neck size, and regular shape were independently associated with complete occlusion. ${ }^{12}$ Ogilvy et $\mathrm{al}^{13}$ developed a scoring system to predict aneurysm recanalization following coil embolization. Larger maximal diameter $(>10 \mathrm{~mm})$, ruptured aneurysm status, the presence of an intra-aneurysmal thrombus, and incomplete obliteration immediately after aneurysm treatment were each associated with a higher risk of recurrence. The presence of assist devices (stents or flow diverters), meanwhile, was associated with a lower risk of recanalization. ${ }^{13,14}$

Jabbour et $\mathrm{al}^{9}$ reported predictors of incomplete aneurysm occlusion at last follow-up after treatment with PED placement. In their study, fusiform shape $(P=.05)$ and, unsurprisingly, shorter follow-up time $(P=.03)$ were independent predictors of incomplete occlusion. However, only 73 aneurysms had angiographic follow-up, with a mean length of 6.1 months. In our study, with a mean follow-up of 19.2 months, the morphology of the aneurysm had no significant effect on occlusion status. However, shorter follow-up length ( $<12$ months) was significantly

AJNR Am J Neuroradiol 38:2295-300 Dec 2017 www.ajnr.org 


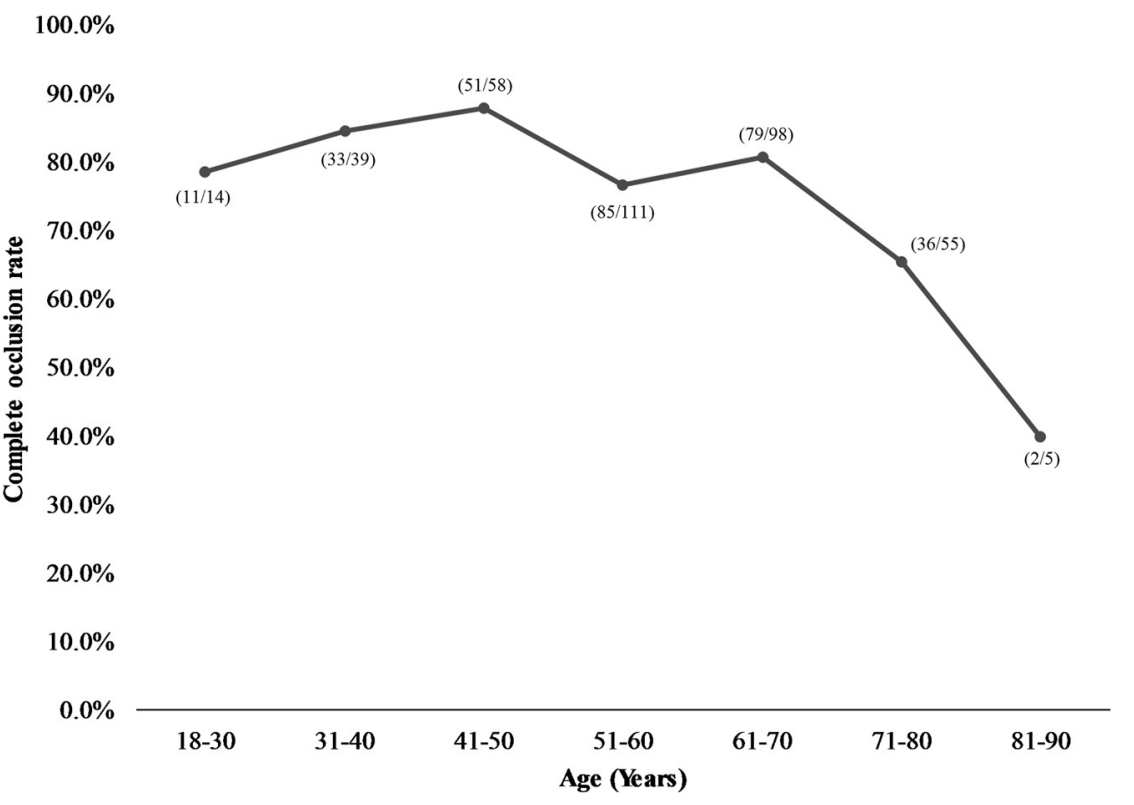

FIGURE. Age-related variation in the rate of complete occlusion following intracranial aneurysm treatment with PEDs.

Table 3: Multivariable logistic regression for predictors of incomplete occlusion at last follow-up

\begin{tabular}{lccc}
\hline \multicolumn{1}{c}{ Parameter } & OR & $\mathbf{9 5 \%} \mathbf{C l}$ & $\boldsymbol{P}$ Value \\
\hline Age (older than $70 \mathrm{yr})$ & 2.0 & $1.1-3.8$ & .03 \\
Nonsmokers & 2.0 & $1.1-3.9$ & .03 \\
PcomA/posterior circulation & 1.6 & $0.9-2.9$ & .13 \\
Maximal diameter $(\geq 21 \mathrm{~mm})$ & 2.1 & $0.9-4.7$ & .08 \\
Length of follow-up $(<12$ months) & 2.1 & $1.2-3.5$ & .007 \\
\hline
\end{tabular}

Note:-PcomA indicates posterior communicating artery.

associated with a lower occlusion rate, which is consistent with previous reports. ${ }^{9,15,16}$

\section{Age-Related Variation in Occlusion Rates}

A meta-analysis of endovascular coiling of intracranial aneurysms in elderly patients (older than 65 years) reported a $66 \%$ complete or near-complete occlusion rate immediately after the procedure, which improved to $74 \%$ at 6- to 12 -month follow-up and $86 \%$ at $>12$ months. ${ }^{17}$ This compares poorly with a $90 \%$ complete or nearcomplete immediate occlusion rate following coil embolization of intracranial aneurysms, when all age groups are considered. ${ }^{18,19}$

In this study, we found that older age (older than 70 years) was a significant predictor of incomplete occlusion at last follow-up. This is the first study to specifically evaluate age and its impact on aneurysm occlusion rates following flow diversion, to our knowledge. There was a tendency for aneurysms to be located within the posterior circulation in this age group compared with younger patients ( $25 \%$ versus $10.9 \%, P=.001$ ), which may influence this finding. Nevertheless, the difference in occlusion rates remained significant after controlling for aneurysm location, which further supported the independent correlation between older age (older than 70 years) and incomplete occlusion. There was no significant difference in the duration of follow-up in older patients compared with younger patients.

As one might expect, as patients age, the risk of complications appears to increase. Brinjikji et $\mathrm{al},{ }^{20}$ in a large multicenter study on complications associated with PED placement, found that complication rates rise as the patient age increases. Patients older than 70 years of age had significantly higher rates of neurologic mortality. Increased age was also associated with higher odds of neurologic morbidity. ${ }^{20}$ Our data found a nonsignificant trend toward increased complications in patients older than 70 years of age.

While the explanation for the lower occlusion rates in the elderly is currently unknown, it is tempting to speculate that this may be due to a deficiency in the endothelial repair pathway. Rouchaud et $\mathrm{al}^{21}$ found that the genes involved in cellular migration and the inflammatory response were upregulated in aneurysms successfully treated with flow diverters in rabbits. Other studies have identified an upregulation of metalloproteinases (critical for endothelial wall remodeling), inflammatory modulators, and growth factors. ${ }^{22}$ In animal models, complete or near-complete endothelialization, which can occur as rapidly as within the first 7 days, is necessary to ensure complete obliteration of the aneurysm. ${ }^{23}$ In a histologic study of giant aneurysms that had undergone flow-diversion treatment and had failed to occlude, lack of endothelialization was predominantly found in patients in their 60 s. $^{24}$ It may be that the endothelial cells in the cerebral vasculature have a diminished capacity for regeneration and migration across the flow-diverter surface, similar to the reduction in neural stem cell proliferation and differentiation potential in the aging brain. ${ }^{25,26}$ While this hypothesis requires further investigation, it raises the tantalizing possibility of coating flow diverters with factors that may enhance endothelialization and may be absent in the cellular milieu of the elderly.

\section{Length of Follow-Up}

As was previously discussed, an important physiologic mechanism for aneurysm occlusion following PED treatment is endothelialization along the length of the device, which results in diversion of blood flow away from the aneurysm sac. ${ }^{27}$ This process is gradual and varies in duration from months to years. Accordingly, longer angiographic follow-ups for aneurysms treated with the PED may be necessary to demonstrate aneurysm occlusion. Prior studies have supported this hypothesis and have found that shorter angiographic follow-up is associated with a decreased aneurysm occlusion rate, with longer duration having the opposite effect. ${ }^{9,15,16}$

\section{Effect of Cigarette Smoking}

Smoking is one of the significant modifiable risk factors for aneurysm formation and increased risk of aneurysm rupture. ${ }^{28-30} \mathrm{Or}-$ tiz et $\mathrm{al}^{31}$ have previously reported a correlation between current smoking status and an increased risk of aneurysm recurrence. However, in that study, the authors stratified smoking status into never/nonsmokers and former/current smokers, despite smoking secession decreasing the risk of vascular inflammation and related malformations. ${ }^{32}$ Therefore, with appropriate stratification of 
current smoking as a separate category, there was no significant effect on aneurysm recurrence or retreatment after endovascular treatment. ${ }^{12,29}$ Similarly, Rouchaud et $\mathrm{al}^{33}$ found no significant correlation between smoking status and aneurysm occlusion following PED placement. In our study, smoking was associated with a higher rate of aneurysm occlusion. Although this finding can be attributed to the relatively small sample size, it might also be related to an increased rate of intra-aneurysmal thrombosis. Smoking is a well-known risk factor for thrombus formation in other pathologies, including cancer, cardiac stent thrombosis, and ischemic stroke. It may be that its prothrombotic effects amplify those of the PED. ${ }^{34-36}$ These findings support an earlier statement by Rouchaud et $\mathrm{al}^{33}$ that smoking status should not be a factor for excluding patients from PED embolization of intracranial aneurysms.

\section{Limitations}

We acknowledge that our study is limited by its retrospective nature with all the inherent biases associated with such a study design. Although the inclusion of multiple institutions improves the generalizability of the findings, it introduces variability in patient management, follow-up protocols, imaging studies used, and evaluation of aneurysm occlusion. Moreover, some aneurysm measurements were missing.

\section{CONCLUSIONS}

Complete occlusion following PED treatment of intracranial aneurysms is influenced by patient characteristics and technical factors. Older age (older than 70 years) and nonsmoking status were independent predictors of incomplete occlusion. While the physiologic explanation for these findings remains unknown, the identification of factors predictive of incomplete aneurysm occlusion following PED placement can help in directing further research on the appropriate clinical use of flow-diversion devices.

Disclosures: Adnan H. Siddiqui-UNRELATED: Board Membership: Intersocietal Accreditation Commission; Consultancy: Codman, Medtronic, Guidepoint Global Consulting, Penumbra, Stryker Neurovascular, MicroVention, W.L. Gore and Associates, Three Rivers Medical, Corindus, Amnis Therapeutics, CereVasc, Pulsar Vascular, The Stroke Project, Cerebrotech Medical Systems, Rapid Medical, Neuravi, Silk Road Medical, Rebound Therapeutics Corp, Claret Medical, Comments: also Principal Investigator/National Steering Committees: Penumbra: 3D Separator Trial, COMPASS Trial, INVEST Trial; Covidien (now Medtronic): SWIFT PRIME and SWIFT DIRECT Trials; MicroVention: FRED Trial, CONFIDENCE Study; Codman \& Shurtleff: LARGE Trial; MUSC: POSITIVE Trial; Stock/Stock Options: StimMed, Valor Medical, Neuro Technology Investors, Cardinal Health, Medina Medical Systems, Buffalo Technology Partners, International Medical Distribution Partners. Elad I. Levy-UNRELATED: Board Membership: Stryker Neurovascular, NeXtGen Biologics, MEDX, Comments: served on acute ischemic stroke Clinical Advisory Board for Stryker Neurovascular, serve on Advisory Board for NeXtGen Biologics and MEDX; no money; Consultancy: Pulsar Vascular; Payment for Development of Educational Presentations: Covidien, Comments: honorarium for training and lectures; Stock/Stock Options: Intratech Medical, NeXtGEn Biologics, Comments: shareholder/ownership interest; Other: Abbott Vascular, Comments: carotid training sessions for physicians. Ajith J. Thomas-UNRELATED: Consultancy: Stryker Neurovascular, Comments: data safety monitoring board*; Expert Testimony: CRICO, Comments: expert witness, neurovascular. *Money paid to the institution.

\section{REFERENCES}

1. McDowell MM, Feroze RA, Ducruet AF. Pipeline Embolization Device: long-term outcome data flows in. World Neurosurg 2016;85: 6-7 CrossRef Medline

2. Health C for D and R: Recently-Approved Devices: Pipeline ${ }^{\text {TM }}$ Em- bolization Device, P100018. https://www.fda.gov/downloads/Advisory Committees/CommitteesMeetingMaterials/MedicalDevices/Medical DevicesAdvisoryCommittee/NeurologicalDevicesPanel/UCM442242. pdf. Accessed August 9, 2016

3. Adeeb N, Griessenauer CJ, Moore J, et al. Pipeline embolization device for recurrent cerebral aneurysms after microsurgical clipping. World Neurosurg 2016;93:341-45 CrossRef Medline

4. Becske T, Kallmes DF, Saatci I, et al. Pipeline for uncoilable or failed aneurysms: results from a multicenter clinical trial. Radiology 2013; 267:858-68 CrossRef Medline

5. Griessenauer CJ, Ogilvy CS, Foreman PM, et al. Pipeline Embolization Device for small intracranial aneurysms: evaluation of safety and efficacy in a multicenter cohort. Neurosurgery 2017;80:579-87 CrossRef Medline

6. Kühn AL, Hou SY, Perras M, et al. Flow diverter stents for unruptured saccular anterior circulation perforating artery aneurysms: safety, efficacy, and short-term follow-up. J Neurointerv Surg 2015; 7:634-40 CrossRef Medline

7. Lin N, Brouillard AM, Keigher KM, et al. Utilization of Pipeline embolization device for treatment of ruptured intracranial aneurysms: US multicenter experience. J Neurointerv Surg 2015;7: 808-15 CrossRef

8. Nelson PK, Lylyk P, Szikora I, et al. The Pipeline embolization device for the intracranial treatment of aneurysms trial. AJNR Am J Neuroradiol 2011;32:34-40 CrossRef Medline

9. Jabbour P, Chalouhi N, Tjoumakaris S, et al. The Pipeline Embolization Device: learning curve and predictors of complications and aneurysm obliteration. Neurosurgery 2013;73:113-20; discussion 120 CrossRef Medline

10. Attali J, Benaissa A, Soize S, et al. Follow-up of intracranial aneurysms treated by flow diverter: comparison of three-dimensional time-of-flight MR angiography (3D-TOF-MRA) and contrast-enhanced MR angiography (CE-MRA) sequences with digital subtraction angiography as the gold standard. J Neurointervl Surg 2016;8: 81-86 CrossRef Medline

11. Boddu SR, Tong FC, Dehkharghani S, et al. Contrast-enhanced timeresolved MRA for follow-up of intracranial aneurysms treated with the Pipeline embolization device. AJNR Am J Neuroradiol 2014;35: 2112-18 CrossRef Medline

12. Chen JX, Lai LF, Zheng K, et al. Influencing factors of immediate angiographic results in intracranial aneurysms patients after endovascular treatment. J Neurol 2015;262:2115-23 CrossRef Medline

13. Ogilvy CS, Chua MH, Fusco MR, et al. Validation of a system to predict recanalization after endovascular treatment of intracranial aneurysms. Neurosurgery 2015;77:168-73; discussion 173-74 CrossRef Medline

14. Ogilvy CS, Chua MH, Fusco MR, et al. Stratification of recanalization for patients with endovascular treatment of intracranial aneurysms. Neurosurgery 2015;76:390-95; discussion 395 CrossRef Medline

15. O'Kelly CJ, Spears J, Chow M, et al. Canadian experience with the Pipeline embolization device for repair of unruptured intracranial aneurysms. AJNR Am J Neuroradiol 2013;34:381-87 CrossRef Medline

16. Yu SC, Kwok CK, Cheng PW, et al. Intracranial aneurysms: midterm outcome of Pipeline embolization device - a prospective study in 143 patients with 178 aneurysms. Radiology 2012;265:893-901 CrossRef Medline

17. Sturiale CL, Brinjikji W, Murad MH, et al. Endovascular treatment of intracranial aneurysms in elderly patients a systematic review and meta-analysis. Stroke 2013;44:1897-902 CrossRef Medline

18. Ferns SP, Sprengers ME, Rooij WJ van, et al. Coiling of intracranial aneurysms: a systematic review on initial occlusion and reopening and retreatment rates. Stroke 2009;40:e523-29 CrossRef Medline

19. Pouratian N, Oskouian RJ Jr, Jensen ME, et al. Endovascular management of unruptured intracranial aneurysms. J Neurol Neurosurg Psychiatry 2006;77:572-78 CrossRef Medline

20. Brinjikji W, Kallmes DF, Cloft HJ, et al. Age-related outcomes following intracranial aneurysm treatment with the Pipeline Emboli- 
zation Device: a subgroup analysis of the IntrePED registry. $\mathrm{J} \mathrm{Neu}$ rosurg 2016;124:1726-30 CrossRef Medline

21. Rouchaud A, Johnson C, Thielen E, et al. Differential gene expression in coiled versus flow-diverter-treated aneurysms: RNA sequencing analysis in a rabbit aneurysm model. AJNR Am J Neuroradiol 2016;37:1114-21 CrossRef Medline

22. Puffer C, Dai D, Ding YH, et al. Gene expression comparison of flow diversion and coiling in an experimental aneurysm model. J Neurointerv Surg 2015;7:926-30 CrossRef Medline

23. Kadirvel R, Ding YH, Dai D, et al. Cellular mechanisms of aneurysm occlusion after treatment with a flow diverter. Radiology 2014;270: 394-99 CrossRef Medline

24. Szikora I, Turányi E, Marosfoi M. Evolution of flow-diverter endothelialization and thrombus organization in giant fusiform aneurysms after flow diversion: a histopathologic study. AJNR Am J Neuroradiol 2015;36:1716-20 CrossRef Medline

25. Madonna R, Novo G, Balistreri CR. Cellular and molecular basis of the imbalance between vascular damage and repair in ageing and age-related diseases: as biomarkers and targets for new treatments. Mech Ageing Dev 2016;159:22-30 CrossRef Medline

26. Yousef H, Morgenthaler A, Schlesinger C, et al. Age-associated increase in BMP signaling inhibits hippocampal neurogenesis. Stem Cells 2015;33:1577-88 CrossRef Medline

27. Griessenauer CJ, Gupta R, Shi S, et al. Collar sign in incompletely occluded aneurysms after Pipeline embolization: evaluation with angiography and optical coherence tomography. AJNR Am J Neuroradiol 2017;38:323-26 CrossRef Medline

28. Andreasen TH, Bartek J Jr, Andresen M, et al. Modifiable risk factors for aneurysmal subarachnoid hemorrhage. Stroke 2013;44:3607-12 CrossRef Medline

29. Brinjikji W, Lingineni $\mathrm{RK}, \mathrm{Gu} \mathrm{CN}$, et al. Smoking is not associated with recurrence and retreatment of intracranial aneurysms after endovascular coiling. J Neurosurg 2015;122:95-100 CrossRef Medline

30. Juvela S, Hillbom M, Numminen $\mathrm{H}$, et al. Cigarette smoking and alcohol consumption as risk factors for aneurysmal subarachnoid hemorrhage. Stroke 1993;24:639-46 CrossRef Medline

31. Ortiz R, Stefanski M, Rosenwasser R, et al. Cigarette smoking as a risk factor for recurrence of aneurysms treated by endosaccular occlusion. J Neurosurg 2008;108:672-75 CrossRef Medline

32. Athyros VG, Katsiki N, Doumas M, et al. Effect of tobacco smoking and smoking cessation on plasma lipoproteins and associated major cardiovascular risk factors: a narrative review. Curr Med Res Opin 2013;29:1263-74 CrossRef Medline

33. Rouchaud A, Brinjikji W, Cloft HJ, et al. Smoking does not affect occlusion rates and morbidity-mortality after Pipeline embolization for intracranial aneurysms. AJNR Am J Neuroradiol 2016;37: 1122-26 CrossRef Medline

34. Aigner A, Grittner U, Rolfs A, et al. Contribution of established stroke risk factors to the burden of stroke in young adults. Stroke 2017;48:1744-51 CrossRef Medline

35. Lemesle G, Tricot $\mathrm{O}$, Meurice $\mathrm{T}$, et al. Incident myocardial infarction and very late stent thrombosis in outpatients with stable coronary artery disease. J Am Coll Cardiol 2017;69:2149-56 CrossRef Medline

36. Salazar Adum JP, Fuentes HE, Lind BB, et al. Predictors of active cancer thromboembolic outcomes: mortality associated with calf deep vein thrombosis. Int Angiol 2017 May 24. [Epub ahead of print] CrossRef Medline 